\title{
The augmenting effect on insulin secretion by oral versus intravenous glucose is exaggerated by high-fat diet in mice
}

\author{
Bo Ahrén, Maria Sörhede Winzell and Giovanni Pacini ${ }^{\mathbf{1}}$ \\ Department of Clinical Sciences, Lund University, BMC B11, SE-221 84 Lund, Sweden \\ ${ }^{1}$ Metabolic Unit, Institute of Biomedical Engineering (ISIB-CNR), Padova, Italy \\ (Correspondence should be addressed to B Ahrén; Email: bo.ahren@med.lu.se)
}

\begin{abstract}
To study whether the incretin effect is involved in adaptively increased insulin secretion in insulin resistance, glucose was infused at a variable rate to match glucose levels after oral glucose $(25 \mathrm{mg})$ in normal anesthetized C57BL/6J female mice or in mice rendered insulin resistant by 8 weeks of highfat feeding. Insulin response was markedly higher after oral than i.v. glucose in both groups, and this augmentation was even higher in high-fat fed than normal mice. In normal mice, the area under the curve $\left(\mathrm{AUC}_{\text {insulin }}\right)$ was augmented from $4 \cdot 0 \pm 0 \cdot 8$ to $8 \cdot 0 \pm 1 \cdot 8 \mathrm{nmol} / 1 \times 60 \mathrm{~min}$ by the oral glucose, i.e. by a factor of $2(P=0 \cdot 023)$, whereas in the highfat fed mice, $A U C_{\text {insulin }}$ was augmented from $0 \cdot 70 \pm 0 \cdot 4$ to $12 \cdot 4 \pm 2 \cdot 5 \mathrm{nmol} / 1 \times 60 \mathrm{~min}$, i.e. by a factor of $17(P<0 \cdot 001)$.
\end{abstract}

To examine whether the incretin hormone glucagon-like peptide-1 (GLP-1) is responsible for this difference, the effect of i.v. GLP-1 was compared in normal and high-fat fed mice. The sensitivity to i.v. GLP-1 in stimulating insulin secretion was increased in the high-fat diet fed mice: the lowest effective dose of GLP-1 was $650 \mathrm{pmol} / \mathrm{kg}$ in normal mice and $13 \mathrm{pmol} / \mathrm{kg}$ in the high-fat diet fed mice. We conclude that 1) the incretin effect contributes by $\sim 50 \%$ to insulin secretion by the oral glucose in normal mice, 2) this effect is markedly exaggerated in insulin-resistant mice fed a high-fat diet, and 3) this augmented incretin contribution in the high-fat fed mice may partially be explained by GLP-1.

Journal of Endocrinology (2008) 197, 181-187

\section{Introduction}

The entero-insular axis represents the physiological regulation of islet function by the gut (Unger \& Eisentraut 1969). A key component of this axis is the incretin effect, which augments increase in insulin secretion following oral versus i.v. glucose (Elrick et al. 1964, Perley \& Kipnis 1967). This effect is partially achieved by gastrointestinal hormones that are released during meal ingestion and augment glucose-stimulated insulin secretion; the two most important being glucagon-like peptide-1 (GLP-1) and glucose-dependent insulinotropic polypeptide (GIP; Vilsboll \& Holst 2004, Drucker 2006). The effect is, however, also partially achieved by autonomic nerves activated by oral glucose. Thus, cholinergic nerves activated during meal ingestion may stimulate insulin secretion (Ahrén 2000). In humans, a study with careful matching of glucose levels after oral versus i.v. administration has shown that the incretin effect contributes to $70-90 \%$ of the insulin response to oral glucose (Nauck et al. 1986). Similarly, also in pigs, the incretin effect contributes to a large degree of the insulin response to oral glucose (Lindkaer- Jensen et al. 1975).

Insulin resistance upregulates insulin secretion, and if this adaptation fails, impaired glucose tolerance or type 2 diabetes develops (Ahrén \& Pacini 2005). The mechanisms of upregulated insulin secretion in insulin resistance may include slight elevation of glucose or free fatty acids (Ahrén \& Pacini 2003). Whether the upregulation of insulin secretion also involves the incretin effect is, however, not known. To study this possibility, incretin contribution to the insulin response to oral glucose was examined in the animal model of high-fat feeding of mice. In this model, insulin resistance develops, and on a long-term basis, this is compensated by increased insulin secretion (Pacini et al. 2001, Ahrén \& Pacini 2002, Winzell \& Ahrén 2004). Previous studies have inferred that there is an upregulation of the insulin response also to non-glucose stimuli such as carbachol (cholinergic agonist), 2-deoxyglucose (activating autonomic nerves), and GLP-1 in this model (Ahrén et al. 1997, Simonsson \& Ahrén 1998). However, these studies have used exogenous administration of secretory agents and, therefore, whether the endogenous incretin effect per se is altered in insulin resistance is still not known.

In this study, we have therefore examined the incretin contribution to insulin secretion during oral glucose in normal and high-fat fed insulin-resistant mice. We estimated insulin secretion after oral and i.v. glucose administration when the glucose levels were matched in these two conditions. We also examined the GLP-1 response to the oral glucose load and the insulin response to low-dose GLP-1 in the model for examining 
the possibility that GLP-1 may contribute to the augmented incretin effect in insulin resistance.

\section{Materials and Methods}

\section{Animals}

Eight-week-old female C57BL/6J mice were obtained from Taconic, Skensved, Denmark, and kept in a temperaturecontrolled room $\left(22^{\circ} \mathrm{C}\right)$ on a $12 \mathrm{~h}$ light: $12 \mathrm{~h}$ darkness cycle. The animals were divided into two groups and given a standard pellet diet (fat $10 \%$, carbohydrate $70 \%$, protein $20 \%$ on an energy basis, total energy $16.1 \mathrm{~kJ} / \mathrm{g}$ ) or a high-fat diet (fat $60 \%$, carbohydrate $20 \%$, protein $20 \%$ on an energy basis, total energy $22 \cdot 0 \mathrm{~kJ} / \mathrm{g}$ ) for 8 weeks. The main difference between the two diets is that the high-fat diet has a high content of lard $(317 \mathrm{~g} / \mathrm{kg})$ and $32 \mathrm{~g} / \mathrm{kg}$ soybean oil compared with the normal diet (19 g/ kg lard and $24 \mathrm{~g} / \mathrm{kg}$ soybean oil), and that the bulk of the normal diet is cornstarch $(299 \mathrm{~g} / \mathrm{kg})$ that is not included in the high-fat diet. Tap water was made available ad libitum. This study was approved by the Ethics Committee in Lund/Malmö.

\section{Oral glucose administration}

The oral glucose test was performed late in the morning after the removal of food from the cages $16 \mathrm{~h}$ earlier. The animals were anesthetized with an i.p. injection of midazolam (0.1 mg/mouse, Dormicum; Hoffman-La-Roche, Basel, Switzerland) and a combination of fluanison $(0.4 \mathrm{mg} / \mathrm{mouse})$ and fentanyl $(0 \cdot 013 \mathrm{mg} /$ mouse; Hypnorm; Janssen, Beerse, Belgium). Thirty minutes later, a blood sample was taken from the retrobulbar, intraorbital, capillary plexus into heparinized tubes. Then, D-glucose (Sigma-Aldrich) was dissolved in saline and administered orally through a gastric tube (outer diameter $1.2 \mathrm{~mm}, 25 \mathrm{mg} / \mathrm{mouse}$ ). The load volume was $10 \mu \mathrm{l} / \mathrm{g}$ body weight. At specific time points after glucose administrations (0, 15, 30, 60, and $120 \mathrm{~min})$, blood samples, $50 \mu \mathrm{l}$ each, were collected. Anesthesia was maintained throughout the $120-$ min study period. Blood was collected in heparinized tubes and immediately centrifuged, whereupon plasma was separated and stored at $-20{ }^{\circ} \mathrm{C}$ until analysis for insulin, glucose and active GLP-1.

\section{i.v. glucose infusion}

The i.v. glucose test was performed late in the morning after the removal of food from the cages $16 \mathrm{~h}$ earlier. The animals were anesthetized as described above. Ten minutes later, the right jugular vein and the left carotid artery were catheterized. The venous catheter was used for infusion of glucose and the arterial catheter for sample collection. After another $30 \mathrm{~min}$, a variable rate glucose infusion was started. The glucose solution was $20 \mathrm{~g} / \mathrm{dl}$ and plasma glucose was determined every $5 \mathrm{~min}$ by the glucose dehydrogenase technique with the use of a
Hemocue (Ängelholm, Sweden). The glucose infusion rate was adjusted to achieve the same glucose level as obtained during the oral glucose test when glucose was administered at a dose of $25 \mathrm{mg}$. Blood samples for the determination of insulin and C-peptide were taken at 0, 15, 30, 60 and $120 \mathrm{~min}$, i.e. at the same time points as in the oral test.

\section{i.v. GLP-1 test}

Animals were anaesthetized as above. Glucose alone $(0.35 \mathrm{~g} / \mathrm{kg})$ or glucose together with GLP-1 (13, 130, or $650 \mathrm{pmol} / \mathrm{kg}$; Sigma) was injected intravenously; blood samples for the analysis of insulin were taken before the i.v. injection and 1 and 5 min after injection.

\section{Analyses}

Plasma insulin was analyzed radioimmunochemically with a double antibody assay using a guinea pig anti-rat insulin antibody, ${ }^{125}$ I-labeled human insulin as the tracer, and rat insulin as the standard (Linco Research, St Charles, MO, USA). Plasma C-peptide was analyzed radioimmunochemically with a double antibody assay using guinea pig anti-rat C-peptide antibody (which cross-reacts to $100 \%$ with mouse C-peptide), rat C-peptide standard, and ${ }^{125} \mathrm{I}$-rat C-peptide as the tracer (Linco). Plasma levels of active GLP-1 were determined by the ELISA technique using monoclonal guinea pig antibodies specific for the active (intact) form of GLP-1 (Linco; Persson et al. 2000). Plasma glucose was measured with the glucose oxidase method using $2,2^{\prime}$-azinobis(3-ethyl-benzothialozine-6-sulfonate) as the substrate, and the absorbance was measured at $420 \mathrm{~nm}$ on a microtiter plate reader (Fluostar/Polarstar Galaxy; BMG Labtechnologies, Offenburg, Germany).

\section{Calculations and statistical analysis}

The values are reported as means \pm s.E.M. area under the curve (AUC) was determined by the trapezoidal rule for glucose, insulin, and C-peptide data during the time period of $0-60 \mathrm{~min}$ after the oral or the matching i.v. glucose infusion. After the i.v. injection of glucose alone or in combination with GLP-1, the acute insulin response (AIR) was estimated as the suprabasal mean 1 and $5 \mathrm{~min}$ insulin, i.e., the mean of insulin at 1 and $5 \mathrm{~min}$ subtracted by the baseline insulin. Statistical comparisons were performed using one-way ANOVA with Bonferroni correction for mass significance as post hoc test. Statistical significance was considered when $P<0 \cdot 05$.

\section{Results}

\section{Baseline levels}

High-fat diet was given for 8 weeks. Table 1 shows that body weight was higher in the high-fat fed mice than in animals 
Table 1 Body weight and baseline levels of glucose, insulin, and Cpeptide in anesthetized C57BL/6J female mice fed normal or highfat diet. Means \pm S.E.M. are shown

\begin{tabular}{|c|c|c|c|}
\hline & $\begin{array}{c}\text { Normal diet-fed } \\
\text { mice }(n=41)\end{array}$ & $\begin{array}{l}\text { High-fat diet fed } \\
\text { mice }(n=33)\end{array}$ & $\boldsymbol{P}$ \\
\hline \multicolumn{4}{|l|}{ Variable } \\
\hline Body weight (g) & $20 \cdot 7 \pm 0 \cdot 2$ & $34 \cdot 7 \pm 0 \cdot 6$ & $<0 \cdot 001$ \\
\hline $\begin{array}{l}\text { Glucose } \\
(\mathrm{mmol} / \mathrm{l})\end{array}$ & $5 \cdot 6 \pm 0 \cdot 2$ & $6 \cdot 6 \pm 0 \cdot 2$ & $<0 \cdot 001$ \\
\hline Insulin (pmol/l) & $147 \pm 12$ & $458 \pm 44$ & $<0 \cdot 001$ \\
\hline $\begin{array}{l}\text { C-peptide } \\
(\mathrm{pmol} / \mathrm{l})\end{array}$ & $497 \pm 30$ & $1310 \pm 76$ & $<0 \cdot 001$ \\
\hline
\end{tabular}

$n$ indicates number of animals. $P$ indicates the probability level of random difference between the two groups.

given the normal diet. Furthermore, plasma glucose levels were slightly elevated as were the levels of insulin and C-peptide. The hyperinsulinemia in spite of the slight hyperglycemia shows the insulin resistance in the high-fat diet fed mice.

\section{Glucose levels during oral and i.v. glucose administration with matched glucose levels}

To estimate the incretin effect, each mouse was given $25 \mathrm{mg}$ glucose orally. This increased the plasma glucose levels to a peak at $15 \mathrm{~min}$ in both the normal diet-fed mice $(15.7 \pm 0.4 \mathrm{mmol} / \mathrm{l})$ and the mice fed the high-fat diet $(17.7 \pm 0.4 \mathrm{mmol} / \mathrm{l})$. Thereafter, the glucose levels fell to reach baseline levels after 120 min (Fig. 1). The $\mathrm{AUC}_{\text {glucose }}$ during the oral glucose was significantly higher in the high-fat fed mice $(605 \pm 31 \mathrm{mmol} /$ $1 \times 120 \mathrm{~min})$ than that in normal mice $(396 \pm 29 \mathrm{mmol} / \mathrm{l} \times$ $120 \mathrm{~min})(P<0 \cdot 001)$. For the estimation of the incretin effect, a variable rate glucose infusion was given intravenously to match the glucose levels after the oral glucose. During the i.v. test, glucose was determined 'bedside' to achieve matching. Figure 1 shows that the matching between the two conditions with regard to glucose, which was excellent in both groups during the initial $60 \mathrm{~min}$ with no significant difference between the two tests. There was a high correlation between the four mean glucose levels during the two tests, in both the normal diet-fed mice $(r=0.98, P=0.022)$ and the high-fat fed mice $(r=0 \cdot 99 ; P=0 \cdot 008)$. By contrast, during the second hour of experiment, the glucose levels obtained during the i.v. test were consistently higher than those during the oral test, despite the fact that the glucose infusion was terminated at $20 \mathrm{~min}$. Figure 1 also shows the glucose infusion rates (stopped at $20 \mathrm{~min}$ ) to achieve the glucose levels matching those of the oral administration and the glucose concentration obtained during the infusion in relation to the desired levels achieved during the oral glucose administration. The total amount of glucose infused was approximately the same in the two groups of mice during the first $15 \mathrm{~min}$ but higher in the mice given the high-fat diet during the interval between 15 and $20 \mathrm{~min}$
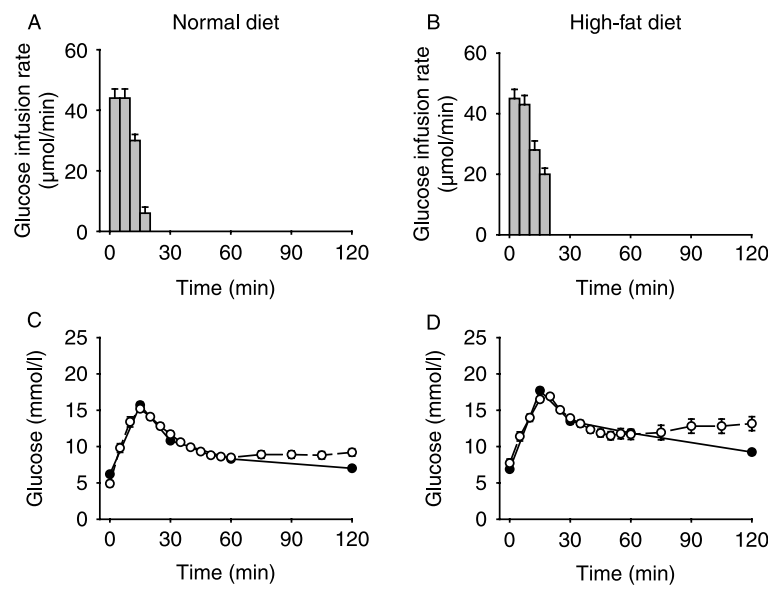

$\longrightarrow-$ Oral glucose
$\ldots-\quad$ Intravenous glucose

Figure 1 Upper panels show the glucose infusion rates during i.v. administration of glucose to match the glucose levels achieved during oral glucose administration at $25 \mathrm{mg}$ in (A) normal mice or (B) high-fat fed mice. Lower panels show the achieved plasma glucose levels during oral or i.v. glucose administration in (C) normal mice or (D) high-fat fed mice. There were 11-30 animals in each group. Means \pm S.E.M. are shown.

$(20 \cdot 2 \pm 2 \cdot 1 \mu \mathrm{mol} / \mathrm{min}$ versus $6 \cdot 1 \pm 1 \cdot 9 \mu \mathrm{mol} / \mathrm{min}, P<0 \cdot 001)$. When correcting for the difference in body weight, the amount of glucose infused was slightly lower in mice fed the high-fat diet $(27.8 \pm 0.7 \mu \mathrm{mol} / \mathrm{g}$ body weight) when compared with normal mice $(33 \cdot 0 \pm 1 \cdot 3 \mu \mathrm{mol} / \mathrm{g}$ body weight, $P=0 \cdot 018)$.

\section{Insulin secretion}

Figure 2 shows insulin and C-peptide levels during the oral and i.v. glucose challenges in the two groups of animals. Insulin and C-peptide levels were significantly higher during the oral tests at $15 \mathrm{~min}$ in both the normal and high-fat fed animals. Table 2 shows AUC of the 0 - to 60 -min time interval, which is the time interval when the glucose levels were perfectly matched. $\mathrm{AUC}_{\text {insulin }}$ and $A U C_{\mathrm{C}-\text { peptide }}$ were significantly higher after the oral glucose challenge than during the i.v. glucose challenge in both the groups. The augmentation of the insulin and C-peptide responses by oral versus i.v. glucose was, however, higher in the high-fat fed mice. Thus, in normal mice, AUC $_{\text {insulin }}$ from the oral glucose was twice as much as that from i.v. glucose $(8 \cdot 0 \pm 1 \cdot 8$ vs $4 \cdot 0 \pm 0 \cdot 8 \mathrm{nmol} / 1 \times 60 \mathrm{~min}$; $P=0.023)$, whereas in the high-fat fed mice, $\mathrm{AUC}_{\text {insulin }}$ was augmented with the oral glucose by a factor of $17(12 \cdot 4 \pm 2 \cdot 5$ vs $0 \cdot 7 \pm 0.47 \mathrm{nmol} / 1 \times 60 \mathrm{~min} ; P<0 \cdot 001)$.

\section{GLP-1 response to oral glucose}

To study the possible contribution by GLP-1 to the augmented insulin response to oral versus i.v. glucose in the 

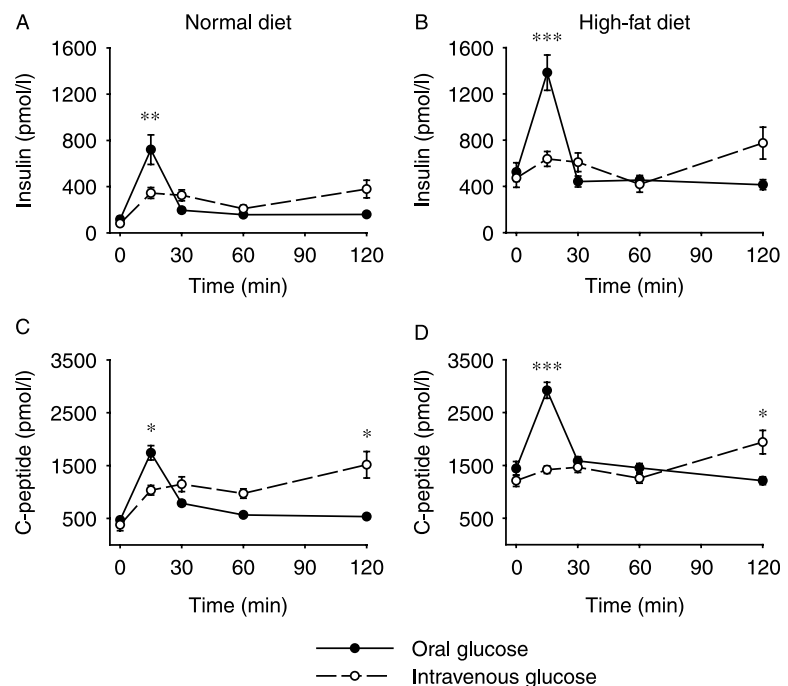

Figure 2 Plasma levels of insulin and C-peptide before and after oral administration of glucose at $25 \mathrm{mg}$ and the corresponding results from the experimental series with i.v. glucose infusion to match the glucose levels achieved during the oral test in anesthetized $\mathrm{C} 57 \mathrm{BL} / 6 \mathrm{~J}$ female mice fed (A and C) normal diet or ( $B$ and $D$ ) high-fat diet. There were 11-30 animals in each group. Means \pm S.E.M. are shown. Asterisks indicate the probability level of random difference between the tests $\left({ }^{*} P<0 \cdot 05,{ }^{* *} P<0 \cdot 01\right.$, $* * * P<0 \cdot 001)$

Table 2 Suprabasal area under the curves for glucose, insulin, and C-peptide during time period 0-60 min following administration of oral glucose $(25 \mathrm{mg})$ or i.v. glucose to match the glucose levels during the oral glucose test in anesthetized C57BL/6J mice fed normal or high-fat diet. Means \pm s.E.M. are shown

\begin{tabular}{|c|c|c|c|}
\hline & Oral glucose & $\begin{array}{l}\text { Intravenous } \\
\text { glucose }\end{array}$ & $\boldsymbol{P}$ \\
\hline \multicolumn{4}{|l|}{ Normal diet } \\
\hline$n$ & 30 & 13 & \\
\hline $\begin{array}{l}\text { Glucose } \\
(\mathrm{mmol} / \mathrm{I} \times \\
60 \mathrm{~min})\end{array}$ & $151 \pm 7 \cdot 4$ & $155 \pm 7 \cdot 4$ & NS \\
\hline $\begin{array}{l}\text { Insulin } \\
(\mathrm{nmol} / \mathrm{I} \times \\
60 \mathrm{~min})\end{array}$ & $8 \cdot 0 \pm 1 \cdot 8$ & $4 \cdot 0 \pm 0 \cdot 8$ & $0 \cdot 023$ \\
\hline $\begin{array}{c}\text { C-peptide } \\
\text { (nmol/l } \times \\
60 \mathrm{~min})\end{array}$ & $17 \cdot 9 \pm 1 \cdot 9$ & $11 \cdot 9 \pm 1 \cdot 2$ & 0.036 \\
\hline \multicolumn{4}{|l|}{ High-fat diet } \\
\hline$n$ & 28 & 11 & \\
\hline $\begin{array}{l}\text { Glucose } \\
(\mathrm{mmol} / \mathrm{l} \times \\
60 \mathrm{~min})\end{array}$ & $187 \pm 8 \cdot 5$ & $184 \pm 8 \cdot 4$ & NS \\
\hline $\begin{array}{l}\text { Insulin } \\
(\mathrm{nmol} / \mathrm{I} \times \\
60 \mathrm{~min})\end{array}$ & $12 \cdot 4 \pm 2 \cdot 5$ & $0 \cdot 70 \pm 0 \cdot 47$ & $<0.001$ \\
\hline $\begin{array}{c}\text { C-peptide } \\
\text { (nmol/IX } \\
60 \mathrm{~min})\end{array}$ & $21 \cdot 2 \pm 2 \cdot 7$ & $2 \cdot 2 \pm 1 \cdot 2$ & $<0.001$ \\
\hline
\end{tabular}

$n$ indicates number of animals. $P$ indicates the probability level of random difference between the two groups. high-fat fed mice, the plasma levels of active GLP-1 were determined before and at 15 and $30 \mathrm{~min}$ after the oral glucose load (25 mg). It was found that the baseline GLP-1 levels were $2 \cdot 7 \pm 0.3 \mathrm{pmol} / 1$ in mice fed a normal diet $(n=32)$ and $2 \cdot 3 \pm$ $0 \cdot 2 \mathrm{pmol} / 1$ in mice fed a high-fat diet $(n=33, P=\mathrm{NS})$. After the oral glucose load, no significant increase in GLP-1 levels was observed in any of the groups; the 15-min GLP-1 levels were $3 \cdot 1 \pm 0 \cdot 8 \mathrm{pmol} / 1$ in normal diet fed mice $(n=11)$ and $2 \cdot 2 \pm 0 \cdot 2 \mathrm{pmol} / 1$ in the high-fat fed mice $(n=11, P=\mathrm{NS})$.

\section{Insulin response to i.v. GLP-1}

To study the effect of i.v. administration of low-dose GLP-1 on insulin secretion, the peptide was injected at 13, 130, or $650 \mathrm{pmol} / \mathrm{kg}$ together with glucose $(0 \cdot 35 \mathrm{~g} / \mathrm{kg})$ in the normal diet fed and high-fat diet fed mice. The glucose levels at the 1 -min time point were $13 \cdot 8 \pm 0.3 \mathrm{mmol} / 1$ in the normal dietfed mice $(n=29)$ and $16 \cdot 1 \pm 0.5 \mathrm{mmol} / 1$ in the high-fat diet fed mice $(n=25)$ in all groups. It was found that the insulin response to i.v. glucose was markedly suppressed in the high-fat diet fed mice compared with normal mice, which is similar to that in the experiments with matching glucose infusion. Thus, as is seen in the upper panel of Fig. 3, the AIR after glucose alone was $938 \pm 101 \mathrm{pmol} / 1$ in the normal mice $(n=9)$ and $44 \pm 7 \mathrm{pmol} / 1$ in the high-fat diet fed mice $(n=7 ; P<0 \cdot 001)$. The i.v. administration of GLP-1 together with glucose increased the insulin response. However, the lowest effective dose of GLP-1 in this respect was different between the groups. Thus, the lowest GLP-1 to achieve an augmentation of the insulin response to i.v. glucose was $650 \mathrm{pmol} / \mathrm{kg}$ in the normal mice but only $13 \mathrm{pmol} / \mathrm{kg}$ in the high-fat diet fed mice, indicating an increased sensitivity to GLP-1 after high-fat feeding. Furthermore, as is seen in the middle panel of Fig. 3, while the fold increase in the AIR was markedly higher in normal mice after glucose alone $(4 \cdot 7 \pm 0 \cdot 8)$ than in the high-fat diet fed mice $(0 \cdot 2 \pm 0 \cdot 2 ; P<0 \cdot 001)$, the fold increase by GLP1 at $650 \mathrm{pmol} / \mathrm{kg}$ together with glucose was not different between the groups (being $6 \cdot 3 \pm 0 \cdot 9$ in normal mice versus $5 \cdot 1 \pm 0.9$ in high-fat diet fed mice, $P=N S$ ). In fact, the markedly suppressed insulin response to glucose in the high-fat fed mice was normalized by GLP-1 at $650 \mathrm{pmol} / \mathrm{kg}$. The increased efficacy of GLP-1 in the high-fat fed mice is also illustrated by calculating the fold increase in AIR by GLP-1 over glucose alone in the two groups (lower panel, Fig. 3). Thus, at $650 \mathrm{pmol} / \mathrm{kg}$, this increase was $25 \cdot 1 \pm 9 \cdot 1$ in the highfat diet versus $1 \cdot 5 \pm 0 \cdot 2$ in normal mice $(P=0 \cdot 001)$.

\section{Discussion}

The main novelty of this study is the demonstration of a large incretin contribution to the insulin response to oral glucose in normal mice, and that this incretin effect is augmented in the insulin-resistant high-fat fed mice. Furthermore, the study also demonstrates an increased sensitivity to exogenous GLP-1 in augmenting glucose-stimulated insulin secretion 

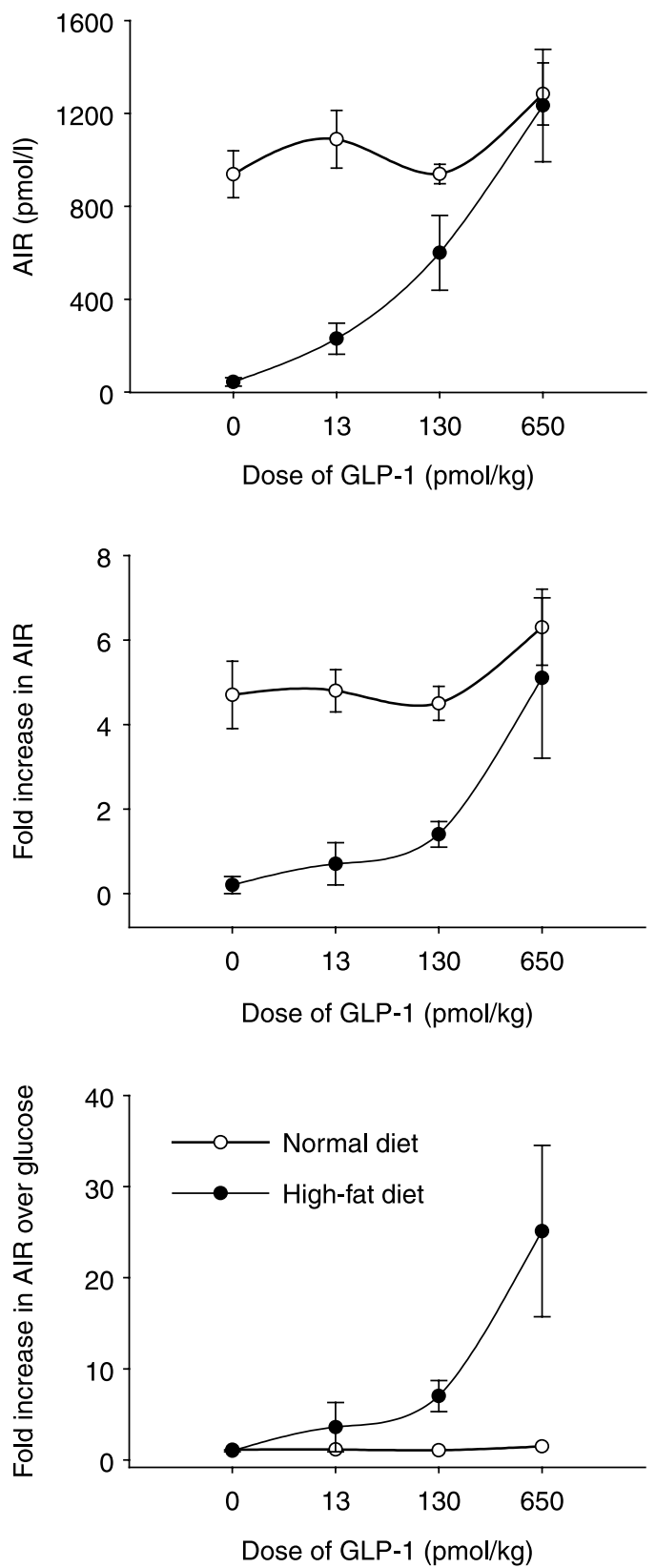

Figure 3 Insulin response to i.v. administration to glucose alone $(0 \cdot 35 \mathrm{~g} / \mathrm{kg})$ or to glucose in combination with GLP-1 at 13, 130, or $650 \mathrm{pmol} / \mathrm{kg}$ in high-fat fed mice and in normal mice. Upper panel shows the AIR (acute insulin response, i.e., the mean suprabasal 1 and 5 min insulin after i.v. administration); middle panel shows the fold increase in AIR over baseline insulin; lower panel shows the fold increase in AIR when related to fold increase by glucose alone (the mean of which was set to 1). There were 3-9 mice in each group. Means \pm S.E.M. are shown.

in the high-fat fed mice, in spite of a suppressed response to glucose alone. This suggests that GLP-1 may contribute to the augmented insulin response to oral glucose in the high-fat fed mice, although other mechanisms may be important as well.
The incretin contribution to the insulin response to oral glucose was evaluated by a variable rate i.v. glucose infusion with the measurement of glucose every $5 \mathrm{~min}$ to match the glucose levels seen during the oral test. The matching between the two conditions was good during the first $60 \mathrm{~min}$. At the end of the second hour, however, the glucose levels were consistently higher during the i.v. test than during the oral test, in spite of the termination of glucose infusion at $20 \mathrm{~min}$. The explanation for this could be the markedly lower insulin levels during the initial $15 \mathrm{~min}$ of the i.v. experiments, which results in a lower glucose clearance and a possible less inhibition of the action of the counterregulatory hormones during the i.v. test. The glucose infusion rate was similar in the two groups to achieve the desired glucose levels, although the total amount of glucose infused per gram body weight was lower in the high-fat fed mice. This was seen in the presence of hyperinsulinemia in the high-fat fed mice. This is a sign of insulin resistance, although it has to be emphasized that the variable rate glucose infusion in the presence of varying insulin levels is not a steady state condition, under which a true insulin sensitivity is possible to determine. Previous studies using the conventional euglycemic-hyperinsulinemic clamp technique have shown that the high-fat fed mice are clearly insulin resistant (Pacini et al. 2001).

The main aim of our study was to compare the contribution by incretin factors to insulin secretion during the oral glucose in normal versus insulin-resistant animals. To that end, we compared the incretin contribution to the insulin response to oral glucose in the normal mice with that in the high-fat fed mice. This model has previously been shown to induce insulin resistance (Pacini et al. 2001, Winzell \& Ahrén 2004). On a short-term basis, such as the 8 -week period used in this study, the high-fat food also results in impaired glucose-stimulated insulin secretion (Ahrén et al. 1997, Simonsson \& Ahrén 1998), whereas on a long-term basis, upregulated insulin secretion develops (Winzell et al. 2007). In the present study, impaired glucose-stimulated insulin secretion was evident in the high-fat fed mice by estimating the insulin response to i.v. glucose. By contrast, we found an increased sensitivity to the incretin effect in the high-fat diet fed mice. Thus, whereas the insulin response in the normal mice was approximately double during the matching 60-min study period after oral glucose compared with i.v. glucose, in the high-fat fed mice, the insulin response to oral glucose was augmented 17-fold when compared with i.v. glucose. This study therefore clearly shows the existence of the incretin effect in mice, and that the augmentation of insulin secretion by oral versus i.v. glucose is more pronounced in the high-fat fed than normal mice. This latter conclusion supports an earlier report that the oral glucose elicits a more pronounced augmentation of glucose-stimulated insulin secretion in the high-fat fed versus control rats, although in that study the glucose levels were not matched between the two conditions (Collier et al. 1985). 
Previous studies have used other approaches than this gold standard technique to quantify the incretin concept in rodents. One approach has been to inhibit incretin hormone action by receptor antagonists or peptide immunoneutralization; these interventions have resulted in glucose intolerance and an insulin response after the oral glucose, which is reduced by $\sim 50 \%$ (Tseng et al. 1999, Filipsson et al. 2000, Lewis et al. 2000). Another approach used mice with genetic deletion of the incretin hormone receptors; such studies have shown that mice with double knockout of the GLP-1 and GIP receptors have reduced the plasma insulin levels $(\sim 50 \%)$ after oral glucose but not after i.v. glucose (Hansotia et al. 2004). A third approach has been to use mice with genetic deletion of neuropeptide receptors, thereby interrupting the neural responses; such studies have shown that mice with genetic deletion of the pituitary adenylate cyclase (PAC1) receptor (the receptor for PAC-activating polypeptide, PACAP) have impaired insulin response to oral administration of glucose (Ahrén 2006). Although these studies present evidence for the existence of the contribution by gut hormones and neuropeptides to the insulin response to oral glucose in rodents, they do not allow quantification of this contribution. Instead, quantification of the contribution by hormones and nerves to prandial insulin secretion requires studies comparable with the human study (Nauck et al. 1986), i.e. estimation of the differences in insulin secretion after careful matching of the glucose levels after oral versus i.v. glucose administration, as performed in this study.

One implication of the results in this study is that other stimulants in concert with glucose elicit a higher insulin secretory response in the high-fat fed mice, in comparison with the blunted insulin response that is seen after stimulation with glucose alone. One possibility would be that the increase in plasma GLP-1 after the oral glucose would be higher in the high-fat diet fed than normal mice. We have previously shown that the oral glucose elicits a GLP-1 response in mice at a glucose load of 50 or $75 \mathrm{mg}$ but not at $17 \mathrm{mg}$ (Persson et al. 2000). We show here that there was no significant increase in GLP-1 levels after oral administration of $25 \mathrm{mg}$ in the mice, and therefore confirm the previous report that in mice an oral dose of $50 \mathrm{mg}$ is required for eliciting a plasma GLP-1 response, when determined by the available assay techniques. This suggests that increased circulating GLP-1 is less likely to contribute to the augmented insulin response to oral glucose in mice. Another option, however, could be an increased response to GLP-1 in the high-fat diet fed mice in spite of the impaired response to glucose alone. Previous studies have suggested that exogenous administration of GLP-1 at a very high, supraphysiological dose $(32 \mathrm{nmol} / \mathrm{kg})$ resulted in a more pronounced insulin response in the high-fat diet fed than normal mice (Simonsson \& Ahrén 1998). In the present study, we examined the insulin response to GLP-1 in the highfat diet fed and normal mice by giving much lower doses that are more related to physiological conditions. We show that the sensitivity to GLP-1 in stimulating insulin secretion was augmented in the high-fat diet fed mice and in fact that GLP-1 could normalize the suppressed insulin response to glucose in this group. This would suggest that the augmented incretin effect in the high-fat diet fed mice is dependent on increased sensitivity of the $\beta$-cells to the incretin rather than to increased release, although this needs to be explored in mice detail.

In conclusion, in this study, we have demonstrated that the incretin effect (mediated by neural or hormonal mechanisms) contributes substantially to insulin secretion to the oral glucose load in mice, and that this effect is augmented in the insulin-resistant high-fat fed mice. This suggests that the adaptive islet response to insulin secretion may involve increased contribution by the incretin effect. The mechanism of this remains to be established, and this study suggests that GLP-1 may contribute.

\section{Acknowledgements}

We are grateful to Kristina Andersson, Lilian Bengtsson, and Lena Kvist for their excellent technical assistance. This work was supported by grants from the Swedish Research Council (grant no. 6834), the Novo Nordisk Foundation, the Albert Påhlsson Foundation, the Swedish Diabetes Foundation, Region Skåne, Medical Faculty, Lund University, and by a grant from Regione Veneto (Biotech DGR 2702/10-09-04). The authors declare that there is no conflict of interest that would prejudice the impartiality of this scientific work.

\section{References}

Ahrén B 2000 Autonomic regulation of islet hormone secretion. Diabetologia 43 393-410.

Ahrén B 2006 The insulin response to gastric glucose is reduced in PAC1 and GRP receptor gene deleted mice. Nutrition, Metabolism, and Cardiovascular Diseases 16 S17-S21.

Ahrén B \& Pacini G 2002 Insufficient islet compensation to insulin resistance vs. reduced glucose effectiveness in glucose-intolerant mice. American Journal of Physiology. Endocrinology and Metabolism 283 E738-E744.

Ahrén B \& Pacini G 2003 Signals adapting the beta cells to changes in insulin sensitivity. In The Metabolic Syndrome: Diabetes, Obesity, Hyperlipidemia and Hypertension, pp 105-113. Eds G Crepaldi, A Tiengo \& A Avogaro. New York: Elsevier.

Ahrén B \& Pacini G 2005 Islet adaptation to insulin resistance. Mechanisms and implications for interventions. Diabetes, Obesity and Metabolism 7 2-8.

Ahrén B, Simonsson E, Scheurink AJW, Mulder H, Myrsén U \& Sundler F 1997 Dissociated insulinotropic sensitivity to glucose and carbachol in high-fat diet-induced insulin resistance in C57BL/6J mice. Metabolism 46 97-106.

Ahrén B, Sauerberg P \& Thomsen C 1999 Increased insulin secretion and normalisation of glucose tolerance by cholinergic agonism in fed C57BL/6J mice. American Journal of Physiology 277 E93-E102.

Ahrén B, Holst JJ, Mårtensson H \& Balkan B 2000 Improved glucose tolerance and insulin secretion by inhibition of dipeptidyl peptidase IV in mice. European Journal of Pharmacology 404 239-245.

Collier GR, Chisholm K, Sykes S, Dryden PA \& O'Dea K 1985 More severe impairment of oral than intravenous glucose tolerance in rats after eating a high fat diet. Journal of Nutrition 115 1471-1476. 
Drucker DJ 2006 The biology of incretin hormones. Cell Metabolism 3 153-165.

Elrick H, Stimmler L, Hlad GJ \& Arai Y 1964 Plasma insulin responses to oral and intravenous glucose administration. Journal of Clinical Endocrinology and Metabolism 24 1076-1082.

Filipsson K, Holst JJ \& Ahrén B 2000 PACAP contributes to insulin secretion after gastric glucose gavage in mice. American Journal of Physiology 279 R424-R432.

Hansotia T, Baggio LL, Delmeire D, Hinke SA, Yamada Y, Tsukiyama K, Seino Y, Holst JJ, Schuit F \& Drucker DJ 2004 Double incretin receptor knockout (DIRKO) mice reveal an essential role for the enteroinsular axis in transducing the glucoregulatory actions of DPP-IV inhibitors. Diabetes 53 1326-1335

Lewis JT, Dayanandan B, Habener JF \& Kieffer TJ 2000 Glucosedependent insulinotropic polypeptide confers early phase insulin release to oral glucose in rats. Demonstration by a receptor antagonist. Endocrinology 141 3710-3716.

Lindkaer-Jensen S, Vagn Nielsen O \& Kuhl C 1975 The enteral insulinstimulation after pancreas transplantation in the pig. Diabetologia $\mathbf{1 2}$ 617-620.

Nauck MA, Homberger E, Siegel EG, Allen RC, Eaton RP, Ebert R \& Creutzfeldt W 1986 Incretin effects of increasing glucose loads in man calculated from venous insulin and C-peptide responses. Journal of Clinical Endocrinology and Metabolism 63 492-498.

Pacini G, Thomaseth K \& Ahrén B 2001 Contribution to glucose intolerance of insulin-independent vs. insulin-dependent mechanisms in mice. American Journal of Physiology 281 E693-E703.

Perley MJH \& Kipnis DM 1967 Plasma insulin responses to oral and intravenous glucose: studies in normal and diabetic subjects. Journal of Clinical Investigation 46 1954-1962.
Persson K, Gingerich RL, Nayal S, Wada K, Wada E \& Ahrén B 2000 Reduced GLP-1 and insulin responses and glucose intolerance after gastric glucose in GRP receptor-deleted mice. American Journal of Physiology 279 E956-E962.

Simonsson E \& Ahrén B 1998 Potentiated B-cell response to non-glucose stimuli in insulin resistant C57BL/6J mice. European Journal of Pharmacology $350243-250$.

Tseng CC, Zhang XY \& Wolfe MM 1999 Effect of GIP and GLP-1 antagonists on insulin release in the rat. American Journal of Physiology 276 E1049-E1054.

Unger RH \& Eisentraut AM 1969 Entero-insular axis. Archives of Internal Medicine 123 261-266.

Vilsboll T \& Holst JJ 2004 Incretins, insulin secretion and type 2 diabetes mellitus. Diabetologia 47 357-366.

Winzell MS \& Ahrén B 2004 The high-fat fed mouse: a model for studying mechanisms and treatment of impaired glucose tolerance and type 2 diabetes. Diabetes 53 S215-S219.

Winzell MS, Magnusson C \& Ahrén B 2007 Temporal and dietary gat content-dependent islet adaptation to high-fat feeding-induced glucose intolerance in mice. Metabolism 56 122-128.

Received in final form 23 December 2007

Accepted 17 January 2008

Made available online as an Accepted Preprint 18 January 2008 